Sports Science

\title{
Quality of coach-athlete relationship and coping as associated factors of stress, anxiety, burnout, and depression symptoms of soccer players in transition to professional: a prospective study
}

\author{
Adson Alves da Silva ${ }^{1}$ (D), Leonardo de Sousa Fortes ${ }^{2}$ (D), Leandro Paim da Cruz Carvalho ${ }^{1}$ (D), \\ José Fernando Vila Nova de Moraes $^{1}$ (D), Rodrigo Gustavo da Silva Carvalho ${ }^{1}$ (D), \\ José Roberto Andrade do Nascimento Júnior ${ }^{1}$ \\ ${ }^{1}$ Universidade Federal do Vale do São Francisco, Petrolina, PE, Brazil. ${ }^{2}$ Universidade Federal \\ da Paraíba, João Pessoa, PB, Brazil.
}

Associate Editor: Ricardo Augusto Barbieri (D, Estácio UniSEB, Ribeirão Preto, SP, Brazil. Email: barbieri_ef@hotmail.com.

\begin{abstract}
Aims: The present study investigated the quality of coach-athlete relationship (CAR) and coping as associated factors stress, anxiety, burnout, and depression symptoms of soccer players in the transition to professional. Methods: Twenty-three athletes from four teams of the 2019 under-20 Bahia State Championship participated in the study. The instruments used were the Coach-Athlete Relationship Questionnaire, the Coping Strategic Athletic Inventory, the Daily Analysis of Life Demands in Athletes, the Competitive State Anxiety Inventory-2R, the Burnout Questionnaire for Athletes, and the Major Depression Inventory. Data analysis was conducted using Generalized Estimation Equations, Pearson's Correlation, and Linear Multiple Regression $(p<0.05)$. Results: Our findings show that from the beginning to the end of the season, CAR and coping strategies were predictors of psychic occurrences. For CAR, the symptoms of anxiety associated with self-confidence and stress symptoms were predicted by Proximity and Complementarity, respectively. As for coping strategies, only the symptoms of stress were predicted by the dimension of facing adversity. Conclusion: From the beginning to the end of the season, the magnitude of the predicting factors over some psychopathologies is enhanced in youth soccer players going through a career transition stage.
\end{abstract}

Keywords: interpersonal relationships, stress, coping, soccer.

\section{Introduction}

Playing in elite soccer is a reality only possible to a strict part of athletes since only $1 \%$ of young players become professional ones ${ }^{1}$. This occurs due to intense training loads, distance from family and friends, dropping out of studies, limitation of social activities, parents' expectations, risk of injuries and ability to manage stress and anxiety $^{2}$. In addition, soccer demands high levels of intermittent efforts, strength, speed, anaerobic capacity, and agility, as well as quick decision making which requires high cognitive demands of athletes ${ }^{3}$.

The last stage that precedes professional soccer is the under-20 category (U-20), which is a transition phase in which high performance is a common demand. It is characterized by an unstable period, and with a great emotional load for athletes ${ }^{4}$. Considering the challenges of this stage, training programs are developed to improve the psychological, physical, physiological, technical, and tactical aspects of the athletes 5 .
However, when the demands exceed the athlete's recovery and adaptability abilities, increased levels of stress can be presented ${ }^{6}$. These, if badly managed, can result in poorly adaptive pre-competitive anxiety symptoms ${ }^{7}$. In more severe cases, in long term, these symptoms can lead to the appearance of burnout syndrome $^{8}$, and even depression.

In order to observe these psychopathologies in soccer athletes, Gomes ${ }^{9}$ stated that the athlete's inability to cope with stress is one of the main barriers to achieving better performance. According to the author, it can cause muscle tension, compromise thinking, decision making, and communication ${ }^{10}$. Román and Saviola ${ }^{11}$ concluded that poorly adaptive anxiety can hinder basic soccer actions, such as passes, shots, game comprehension, and technical/tactical understanding. Technical and tactical execution can also vary according to the importance given to the athletes' performance. Moreover, high training loads, highly competitive levels, number of matches, pressure for high performance throughout the whole season, 
and failure in performance affect the athletes' mental health $^{12}$.

On the other hand, studies suggest that a good relationship with colleagues and leaders can positively influence the performance and mental health of athletes ${ }^{13}$. In this perspective, Pensgaard et al. ${ }^{14}$ investigated the influence of the quality of the coach-athlete relationship (CAR), concluding that a high-quality CAR can decrease perceived stress and attenuate the risk of overuse injuries in muscles, tendons, and ligaments, highly demanded in soccer. CAR is an instrumental construct that measures how athletes perceive the quality of their relationship with the coach, and this occurs through interpersonal parameters of proximity, commitment, and complementarity ${ }^{15}$. A recent study developed by Moen and Myhre ${ }^{16}$ found that a good relationship with the coach is effective in the prevention of psychic occurrences.

However, elite athletes also possess their own resources to cope with the most varied stressing agents in elite sports, denominated coping abilities ${ }^{17}$. Folkman et al. ${ }^{18}$ affirmed that coping abilities are a set of cognitive and behavioral efforts, and the process of cognitive confrontation helps athletes to overcome stress agents ${ }^{19}$. Pires et al. ${ }^{20}$, concluded that coping strategies could vary throughout the season, and the improvement of these strategies could avoid burnout.

Considering that the above-cited psychopathologies could negatively impact elite athletes' performance and mental health ${ }^{4}$. As well as the interpersonal relationship with coaches and leaders ${ }^{15}$, and the coping abilities managed by athletes can protect from the negative effects caused by stress ${ }^{21}$. It is also known that, to date, no study has sought to analyze the responses of the relationships between these variables as a function of the time of the season in athletes in career transition. That said, a detailed analysis of the predictive role of CAR and coping strategies on the mental health of elite athletes' is necessary.

In this scenario, the present study aims to collaborate with literature and sports professionals, as it aims to guide these professionals to value the improvement of interpersonal relationships, as well as to guide youth athletes to improve their behavioral cognitive abilities with the purpose of protecting mental health, especially in the transition phase to the elite of the modality.

In this perspective, the aim of the present study was to investigate the predictive role of CAR quality and coping strategies on stress, symptoms of anxiety, burnout, and depression of soccer players in the transition to professional. The hypothesis of the study was that: (1) the moment of the season would have an impact on the quality of CAR and strategies of copings, as well as on the levels of stress, anxiety, burnout, and depression; and (2) the quality of CAR and coping strategies would have a predictive role on symptoms of stress, anxiety, burnout, and depression.

\section{Methods}

\section{Study design}

The present study is observational, descriptive with a prospective design, and empirical research with associative strategy. The study was developed and structured using the guidelines of the Strengthening the Reporting of Observational Studies in Epidemiology (STROBE) for observational researches ${ }^{22}$.

\section{Participants and sample size}

The four best-placed teams of the 2019 U-20 Bahia State Championship were invited to participate in the study. The participants were selected in a non-probabilistic way and by convenience. The collection of data was performed in visits to each participant's soccer team. The first data collection occurred at the beginning of the season, between the months of April and May, while the second collection of data was performed at the end of the season, between October and November. Data were collected in each team's training center, on dates that were previously scheduled with the team's managers. The following inclusion criteria were adopted: 1) being part of the team for at least three months; 2) being a registered athlete for more than one year; and 3) being enrolled in the U-20 Bahia State Championship, which is the main competition of the category in the State of Bahia. The exclusion criteria were not participating in both moments of the research (beginning or end of the season).

An a priori sample size calculation was performed using the software GPower 3.0.10, based on the value of the correlation between CAR and coping with anxiety, burnout, depression, and stress. The calculation indicated a minimum of 21 participants, with a statistical power of $80 \%$ and a significance level of $p<0.05$. The sample calculation was based on the parameters postulated by Hickey et al. $^{23}$, given that, this power and confidence intervals are commonly used in sample calculations. Considering the sample size calculation, at the first moment of data collection 94 athletes participated, from which 71 were excluded for not being part of their teams at the end of the season. At the second moment, 78 athletes participated, from which 48 were excluded for not being part of their teams at the beginning of the season. When analyzing all respondents, 23 athletes from the four participating teams were present in both moments of data collection. Throughout the 2019 season, the same technical committees were maintained at the 4 clubs involved in the research.

\section{Instruments}

Coping strategies

The Brazilian version of the Athletic Coping Skills Inventory-28 (ACSI-28BR), validated for the Brazilian 
context by Miranda et al. ${ }^{24}$ was used. This instrument has 28 items distributed in seven dimensions with 4 items each. The dimensions of the ACSI-28BR were defined as follows: Peaking under Pressure (measures the athlete's success under pressure); Freedom from Worry (measures how much the athlete does not worry); Coping with Adversities (measures the athlete's success when going through difficult times); Concentration (measures the athlete's ability to concentrate); Goals sitting/Mental preparation (measures how much the athlete can formulate goals and prepare mentally); Confidence and Achievement Motivation (measures how confident and motivated the athlete) and Coachability (measures the athlete's ability to evolve during training). The items are answered in a Likert type scale from 0 (almost never) to 3 (almost always), varying from 0 to 12 points in each dimension. The sum of the subscales is denominated Personal Coping Resource. The results of this scale in its adapted version revealed satisfactory reliability with loads higher than 0.40 and indexes with good adjustments $\left[\chi^{2}(148)=336.776 ; \chi^{2} / \mathrm{df}\right.$ $=2.27$; CFI $=0.916$; TLI $=0.892 ;$ RMSEA $=0.067$ (C.I. $0.058-0.077)$; SRMR $=0.114]^{24}$. The reliability analysis was performed and presented acceptable results for the present study $(\alpha=0.74)$.

Burnout

The Brazilian version of the Athlete Burnout Questionnaire was used. The original instrument was developed specifically to evaluate burnout in athletes by Raedeke and Smith $^{25}$ and its Brazilian version was validated by Pires et al. ${ }^{26}$. The questionnaire is composed of 15 items and three subscales that evaluate the frequency of feelings related to burnout, being: physical and emotional exhaustion (PEE) ("I am exhausted by the physical and emotional demands of sport"); Reduced sense of accomplishment (RSA) ("No matter what I do, I don't perform it like I should"); Sports Devaluation (SD) ("I have negative feelings towards sport"). The answers are given in a likert scale from "never" (1) to "almost always" (5). The results of this scale, in its adapted version, revealed satisfactory reliability $(\alpha>0.70)$ and indexes with good adjustment $\left[\chi^{2}(87)=188.9 ; \mathrm{CFI}=0.95 ; \mathrm{GFI}=0.90 ; \mathrm{NNFI}=0.94\right.$; $\mathrm{TLI}=0.89 ; \mathrm{RMSEA}=0.069]^{26}$. The analysis of reliability was performed and presented acceptable results for the present study $(\alpha=0.82)$.

Coach-athlete relationship quality

The Coach-athlete Relationship Questionnaire (CART-Q), originally developed by Jowett and Ntoumanis $^{27}$ and validated to the Brazilian sports context by Vieira et al. ${ }^{28}$ was used. This questionnaire evaluates the perception of the athlete regarding his/her relationship with the coach. The scale is composed by 11 items distributed in three dimensions, being: Proximity, Commitment; and Complementarity. The answers are given in a 7- point Likert scale from "totally disagree" (1) to "totally agree" (7). The results of this scale in its adapted version revealed satisfactory reliability (from $\alpha=0.70$ to $\alpha=0.83$ ) and indexes with good adjustment $\left[\chi^{2} \quad(36=69.93\right.$; $\chi^{2} / \mathrm{df}=2.18 ;$ CFI $=0.94 ;$ GFI $=0.93 ;$ TLI $=0.92 ;$ RMSEA $=0.08]^{28}$ The analysis of reliability were performed and presented acceptable results for the present study $(\alpha=0.95)$.

\section{Pre-competitive anxiety}

The frequency dimension of the Competitive State Anxiety Inventory-2R (CSAI-2R), originally developed by Martens et al. ${ }^{29}$ and validated for the Brazilian context by Fernandes et al. ${ }^{30}$ was used. This instrument is composed of 16 items distributed in three subscales, being: cognitive anxiety ("I am worried because I may not perform as well as I could in this competition"); somatic anxiety ("I feel my body tense"); and self-confidence ("I feel self-confident"). The results of this scale in its adapted version revealed satisfactory reliability $(\alpha>0.70)$ and indexes with good adjustment $(\mathrm{CFI}=0.959$; GI $=0.924$; RMSEA $=0.044)^{30}$. The analysis of reliability was performed and presented acceptable results for this sample $(\alpha=0.77)$.

Stress

The Daily Analysis of Life Demands in Athletes (DALDA) developed by Rushall ${ }^{31}$ and adapted to the Portuguese language by Moreira and Cavazzoni ${ }^{32}$ was used. The DALDA is divided into parts $\mathrm{A}$ and $\mathrm{B}$, in order to identify the sources of stress and symptoms of stress, respectively. The items are answered through one of the options: a) "worse than normal"; b) "normal"; and c) "better than normal". In order to quantify the symptoms of stress, only the responses with option "a" were calculated. Thus, the sum of the 25 items was configured as the mean for symptoms of stress. The analysis of reliability was performed and presented acceptable results for this sample $(\alpha=0.79)$.

Depression.

The Major Depression Inventory (MDI), translated and adapted to the Portuguese language by Parcias et al. ${ }^{33}$ was used. It includes 10 symptoms of depression from the International Classification of Diseases (ICD-10), evaluating the severity of depressive symptoms. The MDI is characterized as a short screening instrument, used in different contexts of research and mental health. The higher the score, the higher is the depressive state. Each item has a minimum score of 0 (never) to 5 (all the time), with a total score of 20 points or more referring to some degree of depression. In the transcultural adaption of the MDI, the author identified an internal consistency of $\alpha=0.91$, demonstrating satisfactory reliability ${ }^{34}$, very similar to the value achieved in the validation to the Portuguese lan- 
guage $(\alpha=0.93)$. The analysis of reliability was performed and presented acceptable results for this sample $(\alpha=0.85)$.

\section{Procedures}

The procedures adopted in the present study agree with the Brazilian National Health Council's research and ethics criteria (Resolution n. 466/12). In addition, the Research and Ethics Committee of the Federal University of Vale do São Francisco, under protocol number 3.079.408, approved the study.

Initially, contact was made with the Soccer Federation of the State of Bahia and with the teams' managers in order to get authorization to collect data with the players enrolled in the U-20 2019 Bahia State Championship. The questionnaires were answered collectively, in a private room, without the presence of the coaches. The duration to answer the questionnaires was of approximately $45 \mathrm{~min}$. The order of the questionnaires was randomized (simple randomization) among participants and no communication between the athletes during the application of the questionnaires was allowed.

\section{Data analysis}

In order to compare the variables in both moments of the season, Generalized Estimation Equations (GEE) were used. The effect size (d) was calculated using the model proposed by $\mathrm{Cohen}^{35}$ adopting the following cut-points: up to 0.30 represents no effect size; $0.30 \leq \mathrm{d}<0.50$ represents a small effect size; $0.50 \leq \mathrm{d}<0.80$ represents a medium effect size and $\mathrm{d} \geq 0.80$ a large effect size, no upper limit. To verify the normality of the data, the Shapiro-Willk test was used. Considering that the data presented a normal distribution, a descriptive presentation was adopted by means " $x$ " and standard deviation (s), with subsequent use of parametric tests. Pearson's correlation was performed to verify the association between the quality of CAR and coping strategies with anxiety, burnout, depression, and stress. According to Cohen ${ }^{36}$, regarding correlations, values between 0.10 and 0.29 are considered small; scores between 0.30 and 0.49 are considered as moderate; and values between 0.50 and 1.0 are interpreted as large. Multiple linear regression models using the backward method for variable entrance (removal criteria $\mathrm{F}=0.10$ ) were conducted to investigate the predictive role of CAR quality and coping strategies on the symptoms of anxiety, burnout, depression, and stress in both moments (beginning and end of season). The Variance Inflation Factors (VIF) were calculated in order to analyze the indicators of multicollinearity (VIF < 5.0). All statistical analysis was performed on SPSS 22.0 adopting a significance level of $\mathrm{p}<0.05$.

\section{Results}

\section{Descriptive data}

Participants presented a mean age of $18.04 \pm 0.5$ years, practiced the sport for $9.0 \pm 2.2$ years, trained a mean of $5.5 \pm 0.5$ days per week with a mean duration of $2.11 \pm 0.19 \mathrm{~h}$ per day, and were part of their teams for $2.6 \pm 3.0$ years. Among the 119 athletes that were excluded, the main reason was the fact that they did not participate in both moments of the collection of data, other reasons included being promoted to the professional team, being dismissed, or fired from the team, and being injured.

The outcomes of the present study were a) the quality of CAR and coping strategies demonstrated its predictive role on stress, and symptoms of anxiety from the beginning to the end of the season; $b$ ) at the beginning of the season, athletes presented symptoms of somatic anxiety of lower magnitude when compared the athletes at the end of the season.

When comparing the athletes' symptoms of burnout, coping strategies, CAR, anxiety, symptoms of depression and stress according to the moment of the season (beginning and end), a significant difference in the symptoms of somatic anxiety was found ( $p=0.02$; $E S=0.70$, representing a medium effect size) (Table 1). It is worth highlighting that athlete at the end of the season showed higher levels of somatic anxiety when compared to the beginning of the season.

When analyzing the correlation between the quality of CAR and coping strategies with the symptoms of anxiety, burnout, depression, and sources and symptoms of the stress of youth soccer players throughout the season (Table 2), it was possible to observe significant correlations between CAR and the psychopathologies only from the beginning to the end of the season $(\mathrm{p}<0.05$, beginning with the end of the season). Being, commitment to stress $(\mathrm{r}=-0.52)$ and complementarity with stress $(\mathrm{r}=-0.42)$.

Coping strategies were correlated with the following symptoms of psychopathologies $(\mathrm{p}<0.05$; beginning with beginning): performance under pressure with cognitive anxiety $(\mathrm{r}=-0.45)$; free of worries with cognitive anxiety $(\mathrm{r}=0.48)$, somatic anxiety $(\mathrm{r}=0.53)$; PEE $(\mathrm{r}=0.42)$, and depression $(\mathrm{r}=0.41)$; facing adversity with cognitive anxiety $(\mathrm{r}=-0.61)$; self-confidence $(\mathrm{r}=0.42)$, and depression $(r=-0.44)$; focus with cognitive anxiety $(r=-0.53)$; and trust/motivation with cognitive anxiety $(r=-0.53)$ and depression $(r=-0.51)$. On the other hand, when comparing the beginning with the end of the season $(p<0.05$; beginning with the end of the season), the following significant correlations were found: free of worries with cognitive anxiety $(r=-0.45)$; facing adversity with symptoms of stress $(r=0.50)$, cognitive anxiety $(r=-0.42)$, self-confidence $(\mathrm{r}=0.48)$ and depression $(\mathrm{r}=0.51)$. 
Table 1 - Comparison of CAR quality, coping, stress, anxiety, burnout and depression at the beginning and end of the season of youth soccer players.

\begin{tabular}{|c|c|c|c|c|c|}
\hline \multirow{3}{*}{ Variables } & \multicolumn{2}{|c|}{ Moment of the season } & \multirow{3}{*}{ p-value } & \multirow{3}{*}{ d } & \multirow{3}{*}{ Scale } \\
\hline & Beginning $(n=23)$ & End $(n=23)$ & & & \\
\hline & $\bar{x}(s)$ & $\bar{x}(\mathbf{s})$ & & & \\
\hline \multicolumn{6}{|l|}{ Quality of CAR } \\
\hline Proximity & $6.27(0.85)$ & $6.31(1.12)$ & 0.88 & -0.04 & $1-7$ \\
\hline Commitment & $5.68(0.70)$ & $5.97(0.98)$ & 0.23 & -0.34 & $1-7$ \\
\hline Complementarity & $6.13(1.14)$ & $6.24(1.08)$ & 0.71 & -0.10 & $1-7$ \\
\hline \multicolumn{6}{|l|}{ Coping } \\
\hline Peaking under pressure & $2.29(0.65)$ & $2.14(0.51)$ & 0.36 & 0.26 & $0-3$ \\
\hline Freedom from worry & $1.37(0.73)$ & $1.47(0.63)$ & 0.59 & -0.15 & $0-3$ \\
\hline Coping with adversities & $1.95(0.61)$ & $1.93(0.57)$ & 0.89 & 0.03 & $0-3$ \\
\hline Concentration & $1.95(0.35)$ & $1.81(0.50)$ & 0.26 & 0.33 & $0-3$ \\
\hline Goals setting/mental preparation & $2.25(0.58)$ & $2.18(0.48)$ & 0.67 & 0.11 & $0-3$ \\
\hline Confidence/motivation & $2.59(0.37)$ & $2.35(0.46)$ & 0.05 & 0.58 & $0-3$ \\
\hline Coachability & $1.46(0.31)$ & $1.48(0.47)$ & 0.85 & -0.05 & $0-3$ \\
\hline Symptoms of stress & $4.80(3.16)$ & $3.60(2.15)$ & 0.24 & 0.45 & $0-1$ \\
\hline \multicolumn{6}{|l|}{ Anxiety } \\
\hline Cognitive anxiety & $2.98(1.32)$ & $2.41(1.06)$ & 0.22 & 0.48 & $1-7$ \\
\hline Somatic anxiety & $2.39(0.89)$ & $2.97(0.80)$ & $0.02 *$ & -0.70 & $1-7$ \\
\hline Self-confidence & $5.80(0.96)$ & $5.46(0.94)$ & 0.21 & 0.36 & $1-7$ \\
\hline \multicolumn{6}{|l|}{ Burnout } \\
\hline PEE & $2.09(0.93)$ & $2.24(0.67)$ & 0.53 & -0.18 & $1-5$ \\
\hline RSA & $2.68(0.62)$ & $2.71(0.51)$ & 0.89 & -0.05 & $1-5$ \\
\hline $\mathrm{SD}$ & $2.41(1.07)$ & $2.39(0.90)$ & 0.93 & 0.02 & $1-5$ \\
\hline Depression & $18.00(6.43)$ & $20.00(11.61)$ & 0.45 & -0.21 & $0-5$ \\
\hline
\end{tabular}

*significant difference $(\mathrm{p}<0.05)$ - Generalized Estimation Equations. Note: PEE $=$ Physical and Emotional Exhaustion; RSA $=$ Reduced Sense of Accomplishment; $\mathrm{SD}=$ Sports Devaluation. $\mathrm{x}=$ mean. $(\mathrm{sd})=$ standard deviation.

Table 3 presents the regression results, thus, the prediction of the dimensions of CAR, at the beginning of the season, on the psychic occurrences at the end of the season $(\mathrm{p}<0.05)$. Regarding the symptoms of anxiety, the results indicated that $\mathrm{CAR}\left(\mathrm{R}=0.49 ; \mathrm{R}^{2}=0.13 ; \mathrm{F}(3,23)=2.097\right.$; $\mathrm{p}=0.13)$ explained $13 \%$ of the variance of the self-confidence dimension. However, proximity $(\beta=-0.78$; $\mathrm{p}=0.04)$ was an inverse significant predictor, and complementarity $(\beta=0.97 ; p=0.02)$ was a direct predictor. Concerning the dimensions of stress, the results showed that CAR $\left(\mathrm{R}=0.68 ; \mathrm{R}^{2}=0.38 ; \mathrm{F}(3,23=5.496 ; \mathrm{p}=0.001\right.$ explained $38 \%$ of its variance. However, proximity $(\beta=0.67 ; p=0.03)$ was significant direct predictors while complementarity $(\beta=-0.84 ; p=0.01)$ was an inverse predictor. The quality of CAR did not present a predictive role on cognitive and somatic anxiety, symptoms of burnout, sources of stress and symptoms of depression in youth soccer athletes at the beginning of the season.

Table 4 presents the regression results regarding the prediction of the dimensions of the strategies of coping at the beginning of the season on the psychic occurrences at the end of the season $(p<0.05)$. Concerning the symp- toms of stress, coping $\left(\mathrm{R}=0.76 ; \mathrm{R}^{2}=0.38 ; \mathrm{F}(7,23)=\right.$ 2.904; $\mathrm{p}=0.03$ ) explained $38 \%$ of its variance, however, only the dimension facing adversity $(\beta=-0.76 ; p=0.03)$ was a significant inverse predictor. Coping strategies did not present a predictive role on the symptoms of burnout, sources of stress, and symptoms of depression in youth soccer athletes at the beginning of the season.

\section{Discussion}

The present study investigated the predictive role of the quality of the CAR and strategies of coping on the symptoms of stress, anxiety, burnout, and depression in U20 soccer athletes from the beginning to the end of the season. The results showed that the quality of CAR and the strategies of coping used by the athletes could predict symptoms of anxiety-related to self-confidence and the symptoms of stress (Tables 2, 3, and 4). Moreover, when comparing data from the beginning and the end of the season, only the symptoms of somatic anxiety increased in youth U-20 soccer athletes (Table 1). 

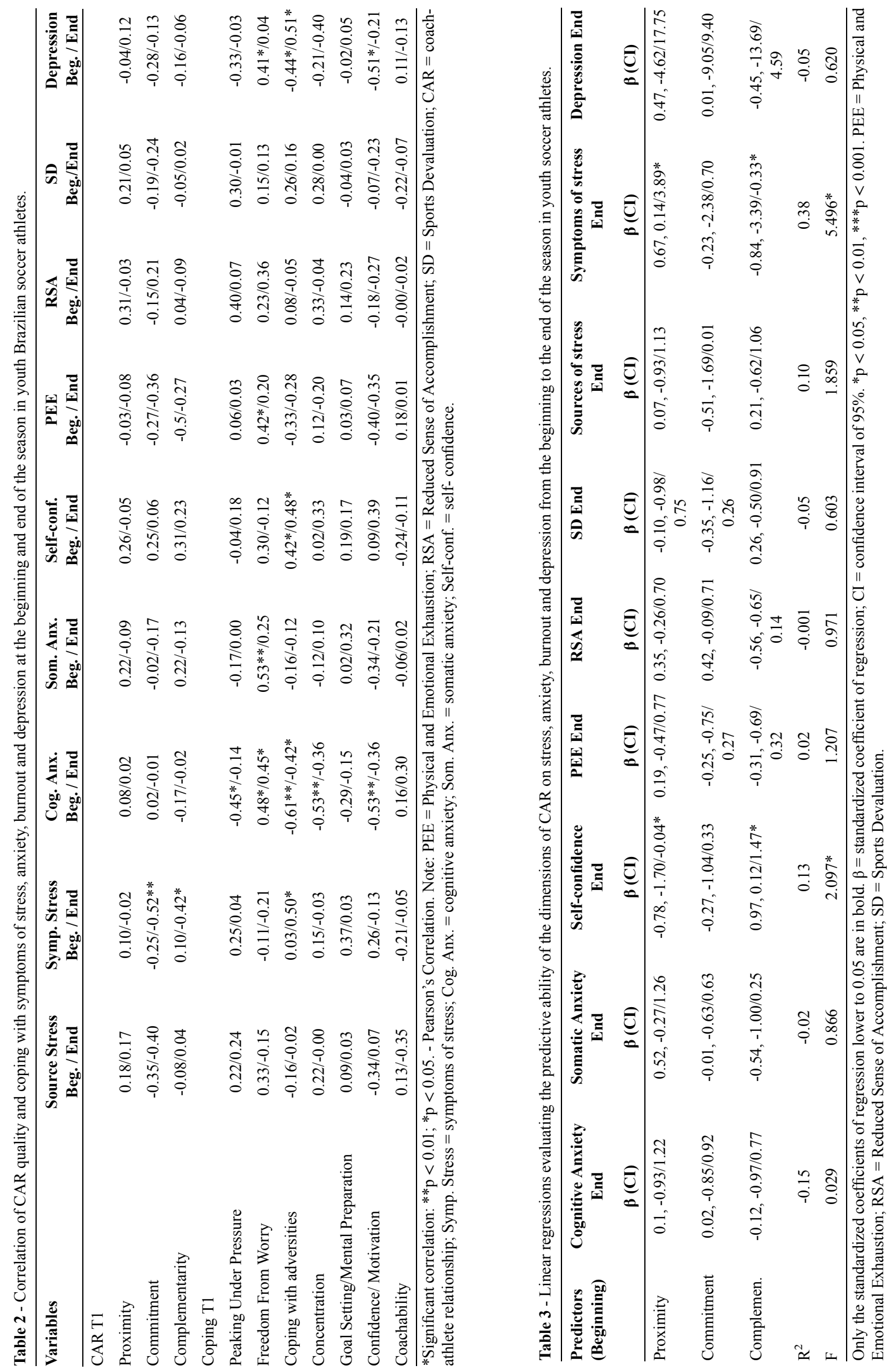


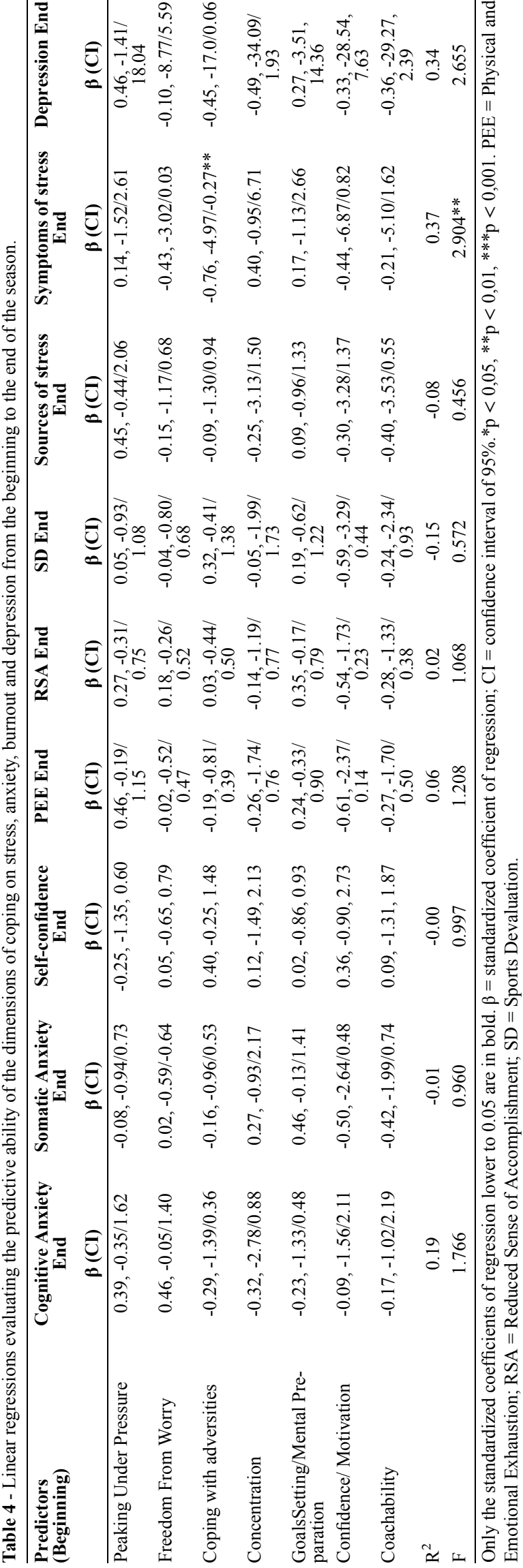

The main finding of the present study was the identification of the predictive power of CAR and coping strategies on the symptoms of stress and anxiety according to the moment of the season in youth U-20 soccer athletes (Tables 3 and 4). Specifically, it was possible to observe that higher proximity to the coach seems to reduce the self-confidence of athletes. However, as athletes and coaches notice that they complement themselves in the daily pursuit of their goals, the self-confidence of the athletes seems to increase (Table 3 ).

These findings corroborate with Wachsmuth et al. ${ }^{37}$ since the authors state that a good relationship with coaches and leaders can increase the athletes' self-confidence. Moreover, being close to the coach also seems to contribute to the increase of the symptoms of stress, however, when the athlete and the coach notice that they complement each other in the daily pursuit of their goals, the symptoms are attenuated (Table 3). These results are like the ones found by Gomes, Faria and Villela ${ }^{38}$, who identified that as the athlete understands that he/she followed well the instructions and functions given by the coach, this seems to increase the autonomous behavior of athletes and the feeling of complementarity among them.

Thus, as the athlete notices that he/she does not perform well what is proposed by the coach, this seems to contribute to an increase in stress levels ${ }^{16}$. Additionally, a dysfunctional relationship between the athlete and the coach can, by itself, be a potential stressor, because athletes expect to be supported by their direct leader. However, Sequeira and Rodrigues ${ }^{39}$ concluded that youth elite athletes referred that being pressured by the coaches to win games is a stressful agent. Lastly, conflicts with coaches are associated with authority divergences, which inhibits players to become more close ${ }^{40}$. However, higher intimacy with coaches has been demonstrated to attenuate the prevalence of higher levels of stress.

Regarding the prediction of coping on the symptoms of stress of youth soccer players throughout the season (Table 4), it was possible to notice that the success of these athletes when dealing with problematic situations (loss of position in the team, receiving red cards and committing major mistakes) seems to attenuate the symptoms of the stress of youth athletes in this career transition stage. These findings strongly agree with Paína et al. ${ }^{4}$, who concluded that U-20 athletes from professional soccer clubs that dealt well with adversities in the sporting context (loss of position in the team, receiving red cards, and committing major mistakes) presented lower scores of stress symptoms. Moreover, feeling confident when dealing with problems has demonstrated a negative association with symptoms of the stress related to sports. Gomes, Faria and Vilela $^{38}$ also stated that a good cognitive evaluation, considered an assumption of good use of coping strategies, was negatively related to aggravating factors related to stress. In addition, the active use of coping focused on the 
problem (an adaptive parameter of coping) has been demonstrated to contribute to the mental health of athletes ${ }^{41}$. Lastly, Britton et al. ${ }^{42}$ identified that stress can directly influence the negative emotions of youth athletes, which, in turn, can reflect negative strategies when facing the problem and, consequently, dissatisfaction with performance.

Even though the present study has important contributions to literature, as well as clubs and sports organizations, it has some limitations. The study was performed with U-20 soccer athletes from the state of Bahia; thus, the results cannot be generalized to the Brazilian scenario. Even though it is a longitudinal study, which allows cause and effect inferences, higher control of variables that may possibly reveal the real protective factor of the psychological elements in question is necessary. Therefore, research involving these constructs in U-20 soccer athletes from different regions of Brazil, and in different moments of the season can contribute to the findings of the present study. Moreover, experimental, and randomized studies could also be important to confirm, with more scientific strength, the protective and predictive power of these psychological elements on the possible psychopathologies in youth U-20 soccer athletes.

\section{Conclusion}

Considering the results found in the present study, it was possible to conclude that the predictive power of CAR and coping on stress and anxiety was increased throughout the season, indicating a higher dependence of a good relationship with the coach and functional use of coping strategies to attenuate the symptoms of these psychic occurrences. Thus, at both the beginning and end of the season, it is necessary to have a good relationship with the coach and to use, as well as possible, the strategies of coping in order to minimize the symptoms and signs of stress and to increase the self-confidence of youth soccer athletes in a career transition phase.

These findings can help coaches, psychologists, and sports professionals to stimulate the development of good relationships with more feedback, cooperation, and help of coaches and athletes. Also, this study can aid youth athletes to deal with stressful agents (loss of position in the team, receiving red cards, and committing major mistakes), since such attitudes can attenuate the symptoms of stress and favor the self-confidence of the athletes. Therefore, it is important that interventions and guidance be performed to better direct youth athletes to develop adequate strategies to face stressing agents and, consequently, decrease the damages caused by the transition stage of the career.

\section{Acknowledgments}

The present study was financed by the Coordenação de Aperfeiçoamento de Pessoal de Nível Superior - Brasil (CAPES) - Financial code 001.

\section{References}

1. Rigo LC, Da Silva DV, Rial CSM. Formação de jogadores em clubes de uma cidade do interior: circulação, escolarização einserção no futebol profissional. Mov. 2018;24:263. doi

2. Melo LBS, Soares AJG, Rocha HPA. Perfil educacional de atletas em formação no futebol no Estado do Rio de Janeiro. Rev Bras Educ Física e Esporte. 2014;28:617-28. doi

3. Hicheur H, Chauvin A, Chassot $\mathrm{S}$, Chenevière X, Taube W. Effects of age on the soccer-specific cognitive-motor performance of elite young soccer players: comparison between objective measurements and coaches' evaluation. PLoS One. 2017;12:e0185460. doi

4. Paína DM, Fechio JJ, Peccin MS, Padovani RDC. Avaliação da qualidade de vida, estresse, ansiedade e coping de jogadores de futebol de campo da categoria sub-20. Cont Clín. 2018;119(1):97 doi

5. Aquino RLQT, Gonçalves LGC, Oliveira LP, Tourinho Filho H, Puggina EF. Effects of 22 weeks of training on functional markers and match performance of young soccer players. Mot Rev Educ Física. 2016;22:93-101. doi

6. Brink MS, Visscher C, Coutts AJ, Lemmink KAPM. Changes in perceived stress and recovery in overreached young elite soccer players. Scand J Med Sci Sports. 2012;22:28592. doi

7. Fortes LS, Fiorese L, Andrade Nascimento-Júnior JR, Almeida SS, Ferreira MEC. Efeito da ansiedade competitiva sobre a tomada de decisão em jovens atletas de voleibol. Psicol Teor e Pesqui. 2019;35:3538. doi

8. Eklund RC, DeFreese JD. Athlete burnout: what we know, what we could know, and how we can find out more. International J Appl Sport Sci. 2015;27:63-75. doi

9. Gomes AR, Bartholomeu JM, Montiel FK, Miguel LF, Carvalho JMH. Adaptação humana no desporto: uma perspetiva transacional. In: Atualização em avaliação e tratamento das emoções. São Paulo, Vetor Ed.; 2013. p. 389-410.

10. Kavanagh J. Stress and performance a review of the literature and its applicability to the military. St Monica, RAND Corp.; 2015.

11. Román S, Savoia M. Pensamentos automáticos e ansiedade num grupo de jogadores de futebol de campo. Psicol Teor e prática. 2003;5:13-22.

12. Caine D, Walch T, Sabato T. The elite young athlete: strategies to ensure physical and emotional health. Open Access J Sport Med. 2016;7:99-113. doi

13. Paradis K, Carron A, Martin L. Development and validation of an inventory to assess conflict in sport teams: the Group Conflict Questionnaire. J Sports Sci. 2014;32:1966-78. doi

14. Pensgaard AM, Ivarsson A, Nilstad A, Solstad BE, Steffen $\mathrm{K}$. Psychosocial stress factors, including the relationship with the coach, and their influence on acute and overuse injury risk in elite female football players. BMJ Open Sport Exerc Med. 2018;4(1):e000317. doi 
15. Jowett S, Nicolas MYS. Unravelling the links between coach behaviours and coach-athlete relationships. Eur J Sport Exerc Sci. 2017;5:10-9.

16. Moen F, Myhre K. Can the working alliance between coaches and athletes explain athlete burnout among junior athletes? Sport J. 2017;19:1-23.

17. Aroni A, Bagni G, Bocchio GL MA. Estresse da iniciação esportiva até profissionalização: uma análise exploratória da trajetória de atletas profissionais de futebol. Rev Bras Futsal e Futeb. 2019;11:263-72.

18. Folkman S. Personal control and stress and coping processes: a theoretical analysis. J Pers Soc Psychol. 1984;46:839-52. doi

19. Fletcher D, Sarkar M. A grounded theory of psychological resilience in Olympic champions. Psychol Sport Exerc. 2012;13:669-78. doi

20. Pires D, Ferreira R, Vasconcelos A. Burnout dimensions, coping strategies and practice time as a federated athlete in professional soccer players. Cuad Psicol del Deport. 2019;19:175-85.

21. Slimani M, Bragazzi NL, Znazen H, Paravlic A, Azaiez F, Tod D. Psychosocial predictors and psychological prevention of soccer injuries: a systematic review and meta-analysis of the literature. Phys Ther Sport. 2018;32:293-300. doi

22. Malta M, Cardoso LO, Bastos FI, Magnanini MMF, Silva CMFP. Iniciativa STROBE: subsídios para a comunicação de estudos observacionais. Rev Saude Publica. 2010;44:559-65. doi

23. Hickey, GL, Grant, SW, Dunning J, Siepe M. Statistical primer: sample size and power calculations - why, when and how? Eur J Cardio-thoracic Surg. 2018;54(1):4-9. doi

24. Miranda R, Coimbra DR, Bara Filho MG, Miranda Júnior MV, Andrade A. Brazilian version (acsi-28br) of athletic coping skills inventory-28. Rev Bras Med do Esporte. 2018;24:130-4. doi

25. Raedeke TD, Smith AL. Development and preliminary validation of an athlete burnout measure. J Sport Exerc Psychol. 2001;23:281-306. doi

26. Pires DA, Brandão MRSC. Validação do questionário de burnout para atletas. J Phys Educ. 2006;17:27-36.

27. Jowett S, Ntoumanis $\mathrm{N}$. The coach-athlete relationship questionnaire (CART-Q): development and initial validation. Scand J Med Sci Sport. 2004;14:245-57. doi

28. Vieira LF, Nascimento Junior JRA, Pujals C, Jowett S, Codonhato R, Vissoci JRN. Adaptação transcultural e propriedades psicométricas do questionário de relacionamento treinador-atleta brasileiro (CART-Q) - versão atleta. Rev Bras Cineantropometria e Desempenho Hum. 2015;17:635. doi

29. Martens R, Robin S, Vealey DB, Burton D. Competitve anxiety in sport. Chanpagni Illions, Hum Kinet Publ. 1990.

30. Fernandes MG, Nunes SAN, Raposo JV, Fernandes HM. Efeitos da experiência nas dimensões de intensidade, direção e frequência da ansiedade e autoconfiança competitiva: um estudo em atletas de desportos individuais e coletivos. Motricidade. 2014;10(2):81-89. doi
31. Rushall, BS. A tool for measuring stress tolerance in elite athletes. J Appl Sport Psychol. 1990;2(1):51-66.

32. Moreira A, Cavazzoni PB. Monitorando o treinamento através do Wisconsin upper respiratory symptom survey -21 e daily analysis of life demands in athletes nas versões em língua Portuguesa. Rev da Educ Física. 2009;20(1):109-19. doi

33. Parcias S, Rosario BP, Sakae T, Monte F, Guimarães ACA, Xavier AJ. Validação da versão em português do Inventário de Depressão Maior. J Bras Psiquiatr. 2011;60:164-70. doi

34. Mulrow CD. Case-finding instruments for depression in primary care settings. Ann Intern Med. 1995;122:913. doi

35. Cohen J. Statistical power analysis. Curr Dir Psychol Sci. 1992;1:98-101. doi

36. Cohen J. Set correlation and contingency tables. Appl Psychol Meas. 1988;12:425-34. doi

37. Wachsmuth S, Jowett S, Harwood CG. Conflict among athletes and their coaches: what is the theory and research so far? Int Rev Sport Exerc Psychol. 2017;10:84-107. doi

38. Gomes AR, Faria S, Vilela C. Anxiety and burnout in young athletes: the mediating role of cognitive appraisal. Scand J Med Sci Sports. 2017;27:2116-26. doi

39. Santos FJLD, Sequeira PJRMD, Rodrigues JDJF. A comunicação dos treinadores de futebol de equipes infanto-juvenis amadores e profissionais durante a competição. Motriz: J Phys Educ. 2012;18:262-72.

40. Shanmugam V, Jowett S, Meyer C. Eating psychopathology amongst athletes: The importance of relationships with parents, coaches and teammates. Int J Sport Exerc Psychol. 2013;11:24-38. doi

41. Dias C, Cruz JF, Fonseca AM. The relationship between multidimensional competitive anxiety, cognitive threat appraisal, and coping strategies: a multi-sport study. Int J Sport Exerc Psychol. 2012;10:52-65. doi

42. Britton DM, Kavanagh EJ, Polman RCJ. A path analysis of adolescent athletes' perceived stress reactivity, competition appraisals, emotions, coping, and performance satisfaction. Front Psychol. 2019;10:1151. doi

\section{Corresponding author}

Adson Alves da Silva. Universidade Federal do Vale do São Francisco, Petrolina, PE, Brazil.

E-mail: alvesadson10@gmail.com.

Manuscript received on May 11, 2021

Manuscript accepted on September 3, 2021

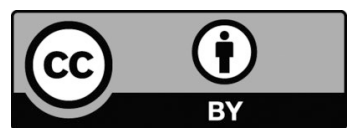

Motriz. The Journal of Physical Education. UNESP. Rio Claro, SP, Brazil - eISSN: 1980-6574 - under a license Creative Commons - Version 4.0 